\title{
Silence Comes at a Cost: Sexual Harassment Reporting in STEM
}

Maria Daniella Douglas* and Barbara C. Bruno, Hawai ‘i Institute of Geophysics and Planetology, University of Hawai ‘i at Mānoa, Honolulu, Hawai'i, 96822, USA

"In order to defeat the darkness, you must bring it into the light." —-Seth Adam Smith, Rip Van Winkle and the Pumpkin Lantern (2016, p. 113)

Sexual harassment claims and their investigations bring unwanted attention to an ugly side of academia. Informing the public of these awful events can paint the institution in a poor light. Such reports can also empower other victims to come forward, potentially leading to more bad press for the school. So, many institutions are understandably loath to publicize the prevalence of sexual misconduct on their campuses. However, this silence comes at a cost, because it communicates that sexually harassing behavior is tolerated. In contrast, regularly informing campus communities of sexual harassment claims and their outcomes communicates intolerance, which can create a safer environment to study and work.

\section{REPORTING COMMUNICATES INTOLERANCE}

The National Academies of Sciences, Engineering, and Medicine (NASEM, 2018) recently published a report aimed at mitigating sexual harassment in higher education. The report states: "There is often a perceived tolerance for sexual harassment in academia, which is the most potent predictor of sexual harassment occurring in an organization... The evidence suggests that the workplace climate is seen as intolerant of sexual harassment when... the campus community is regularly informed about how the institution is handling/attending to claims" (p. 3).

This key recommendation suggests that institutions should regularly inform the campus community about the number and types of sexual harassment claims that have been reported, how these claims are being investigated, and their outcomes, including disciplinary measures taken. This creates the perception of sexual harassment intolerance, which is critically important in spreading awareness of resources for sexual harassment victims and preventing future incidents of harassment. These reports also hold the institutions accountable for protecting their students and employees and adhering to their own set policies and procedures.

However, no law requires universities to release such reports. The Clery Act (1990) requires U.S. colleges and universities to publish annual reports on campus crimes. Since many types of sexual harassment are not considered crimes, they are not included in the mandated Clery reports. Additionally, the Clery Act does not require reporting on the status of pending claims. Thus, Clery reports are a good first step, but fall well short of meeting the NASEM (2018) standard for sexual harassment reporting.

Similarly, many institutions conduct campus climate surveys, which are largely aimed at gathering anonymous data to inform policies regarding campus sexual misconduct (Association of American Universities, 2015). However, because these surveys are anonymous, institutions cannot properly investigate survey responses, let alone impose sanctions on perpetrators.

Last year, NASEM (2019) launched an Action Collaborative to address and prevent sexual harassment, in partnership with more than sixty higher education institutions and research organizations. The Action Collaborative may be the next big step in the battle against sexual harassment in higher education as it develops research-based policies and promising practices that promote a campus culture of civility and respect.

\section{A LOOK AT THE TOP 100 GEOSCIENCE UNIVERSITIES}

While there are no laws that require U.S. universities to publicly release annual reports on sexual harassment, NASEM (2018) strongly encourages them to do so. So, how many institutions are actually doing this? To find out, we searched the websites of the top 100 geoscience universities (Nature Index, 2019) to see how many had released at least one report since January 2019 that follows NASEM guidelines. Specifically, we looked for reports that included data on (1) the number of sexual harassment claims made against students and faculty; (2) their investigations and outcomes; and (3) sanctions taken on claims that were found to have cause.

Several search terms were used in addition to the name of the institution, including sexual harassment, sexual misconduct, annual report, and Title IX. If the report could not be found within 30 minutes of active searching, then the institution was determined not to have publicly released a report.

Of the top 100 geoscience universities in the U.S., we found only 26 to have released reports that met all three criteria (Table 1). An additional eight institutions released reports that met two of the three criteria; most of these did not describe the sanctions imposed (Table 2). Thus, two-thirds (66\%) of the top 100 geoscience institutions fall considerably short of the NASEM (2018) recommendation.

In contrast, the vast majority (eight, or $80 \%$ ) of the top ten geoscience institutions released detailed reports on sexual misconduct, and many announced the publication of these reports as an important step in promoting public safety and institutional accountability. Some of these schools noted an increase in sexual misconduct reporting

GSA Today, v. 30, https://doi.org/10.1130/GSATG463GW.1. Copyright 2020, The Geological Society of America. CC-BY-NC.

*Corresponding author: dd9496@hawaii.edu 
TABLE 1. UNIVERSITIES AMONG THE TOP 100 U.S. GEOSCIENCE UNIVERSITIES THAT

HAVE PUBLICLY RELEASED REPORTS

ON SEXUAL MISCONDUCT THAT MEET THE NASEM (2018) CRITERIA

\begin{tabular}{ll}
\hline \hline Ranking & Name of Institution \\
\hline 1 & University of Colorado Boulder \\
5 & Columbia University in the City of New York ${ }^{A C}$ \\
6 & The University of Texas at Austin \\
7 & Yale University \\
8 & Massachusetts Institute of Technology ${ }^{A C}$ \\
9 & Stanford University ${ }^{A C}$ \\
10 & University of California, Los Angeles ${ }^{A C}$ \\
14 & University of Michigan ${ }^{A C}$ \\
18 & University of California, Davis \\
19 & Princeton University \\
20 & University of California, Irvine \\
24 & Cornell University \\
26 & University of California, Santa Cruz \\
29 & The University of lowa \\
34 & Johns Hopkins University ${ }^{A C}$ \\
41 & Purdue University ${ }^{A C}$ \\
42 & The University of Chicago ${ }^{A C}$ \\
43 & Brown University \\
49 & Indiana University \\
54 & University of Alaska Fairbanks ${ }^{A C}$ \\
62 & The University of North Carolina at Chapel \\
70 & Hill \\
90 & The University of Tennessee, Knoxville ${ }^{A C}$ \\
93 & University of Missouri \\
96 & Northwestern University ${ }^{A C}$ \\
98 & Rensselaer Polytechnic Institute \\
\hline AC- denotes schools that are NASEM 2019 Action \\
Collaborative members.
\end{tabular}

TABLE 2. UNIVERSITIES AMONG THE TOP 100 U.S. GEOSCIENCE UNIVERSITIES THAT HAVE PUBLICLY RELEASED REPORTS ON SEXUAL MISCONDUCT THAT PARTIALLY ADDRESS THE NASEM (2018) CRITERIA

\begin{tabular}{ll}
\hline \hline Ranking & Name of Institution \\
\hline 3 & University of California, Berkeley ${ }^{A C}$ \\
15 & Harvard University \\
16 & University of Maryland, College Park \\
31 & Duke University \\
36 & Virginia Polytechnic Institute and State \\
39 & University \\
51 & University of California, Santa Barbara ${ }^{A C}$ \\
99 & University of Montana \\
\hline AC-denotes schools that are NASEM 2019 Action \\
Collaborative members.
\end{tabular}

following the release of annual reports (e.g., Yale shared that their reported complaints had doubled), and this can draw unwanted media attention. However, such a reporting increase can and should be viewed positively, because greater awareness of resources and support for victims encourages reporting (Davila IV and Steinkamp, 2019). Similarly, Stanford provost Persis Drell shared, "It is also my hope that by making surveys and reports visible and accessible we will encourage anyone experiencing unwanted sexual conduct to come forward so that it can be addressed" (Drell, 2019).

Of the 60+ NASEM Action Collaborative institutions, 38 are among the top 100 geoscience universities. Of those 38, 19 have released detailed sexual misconduct reports since January 2019. Since joining the Action Collaborative, several universities have pledged to publish reports within the coming year.

\section{A CALL TO ACTION}

To prevent sexual harassment, higher education institutions must be perceived to be intolerant of such harassment. Informing the campus community of sexual harassment allegations, how these claims have been handled, and the outcomes of these claims clearly communicates that sexual harassment is not tolerated (NASEM, 2018). Such reports also hold universities accountable for upholding the policies they have put in place to protect their communities. We are therefore issuing a call to action for all universities, and particularly those 100 top geoscience universities, to follow the lead of the top ten geoscience universities and Action Collaborative members to produce such annual reports. The power is in the hands of the institution to pave the way for a future where fears of discrimination or harassment no longer impede success.

\section{ACKNOWLEDGMENTS}

This is School of Ocean and Earth Science and Technology contribution no. 10973. Funding was provided by NSF \#1565950. This manuscript benefited from constructive feedback provided by M. Grabowski.

\section{REFERENCES CITED}

Association of American Universities (AAU), 2015, AAU Climate Survey on Sexual Assault and Sexual Misconduct, https://www.aau.edu/key-issues/ aau-climate-survey-sexual-assault-and-sexual -misconduct-2015 (accessed 4 May 2020).

Clery Act, 1990, Jeanne Clery Disclosure of Campus Security Policy and Campus Crime Statistics Act of 1990, 20 U.S.C. §1092(f).

Davila IV, J., and Steinkamp, A., 2019, Sexual misconduct complaints doubled since 2017: Yale Daily News, https://yaledailynews.com/blog/ 2019/09/20/sexual-misconduct-complaints -doubled-since-2017/ (accessed 4 May 2020).

Drell, P., 2019, 2018-19 Title IX/Sexual Harassment Report: https://provost.stanford.edu/2019/ 12/02/2018-19-title-ix-sexual-harassment-report/ (accessed 4 May 2020).

National Academies of Sciences Engineering and Medicine (NASEM), 2018, Sexual harassment of women: Climate, culture, and consequences in academic sciences, engineering, and medicine: Washington, D.C., National Academies Press, https://www.nap.edu/catalog/24994/sexual -harassment-of-women-climate-culture-and -consequences-in-academic (accessed 4 May 2020)

NASEM, 2019, Action Collaborative on Preventing Sexual Harassment in Higher Education: Washington, D.C., National Academies Press, https:// www.nationalacademies.org/our-work/action -collaborative-on-preventing-sexual-harassment -in-higher-education (accessed 4 May 2020).

Nature Index, 2019, 2019 tables: Institutions-Earth \& environmental sciences—academic, https://www .natureindex.com/annual-tables/2019/institution/ academic/earth-and-environmental/countries -United\%20States\%20of\%20America\%20(USA) (accessed 4 May 2020).

Smith, S.A., 2016, Rip Van Winkle and the Pumpkin Lantern: Self-published, 254 p.

Manuscript ReCeived 22 Apr. 2020

MANUSCRIPT ACCEPTED 28 Apr. 2020 